Mikrochim Acta. 2016 February 1; 183(2): 611-616. doi:10.1007/s00604-015-1685-3.

\title{
Quantum Dot-Modified Paper-Based Assay for Glucose Screening
}

\author{
Gema M. Durán ${ }^{1,2}$, Tomás E. Benavidez ${ }^{3}$, Ángel Ríos ${ }^{1}$, and Carlos D. García ${ }^{3,}$ \\ ${ }^{1}$ Department of Analytical Chemistry, University of Castilla - La Mancha, Avenue Camilo José \\ Cela s/n, Ciudad Real 13004, Spain \\ ${ }^{2}$ IRICA (Regional Institute of Applied Scientific Research), Avenue Camilo José Cela s/n, Ciudad \\ Real 13004, Spain \\ ${ }^{3}$ Department of Chemistry, Clemson University, 219 Hunter Laboratories, Clemson, S.C. 29634, \\ USA
}

\begin{abstract}
A simple and inexpensive method to fabricate a colloidal $\mathrm{CdSe} / \mathrm{ZnS}$ quantum dots-modified paperbased assay for glucose is herein reported. The circular paper sheets were uniformly loaded and displayed strong fluorescence under a conventional hand-held UV lamp (365 nm). The assay is based on the use of glucose oxidase enzyme (GOx), which impregnated the paper sheets, producing $\mathrm{H}_{2} \mathrm{O}_{2}$ upon the reaction with the glucose contained in the samples. After 20 min of exposure, the fluorescence intensity changed due to the quenching caused by $\mathrm{H}_{2} \mathrm{O}_{2}$. To obtain a reading, the paper sheets were photographed under $365 \mathrm{~nm}$ excitation using a digital camera. Several parameters, including the amount of QD, sample $\mathrm{pH}$, and amount of GOx were optimized to maximize the response to glucose. The paper-based assay showed a sigmoidal-shaped response with respect to the glucose concentration in the $5-200 \mathrm{mg} \cdot \mathrm{dL}^{-1}$ range (limit of detection of 5 $\mu \mathrm{g} \cdot \mathrm{dL}^{-1}$ ), demonstrating their potential use for biomedical applications.
\end{abstract}

\section{Graphical abstract}

\section{0 00000000000}

\begin{abstract}
A simple and inexpensive paper-based assay for glucose is herein reported. Several parameters, including the amount of QD, sample $\mathrm{pH}$, and amount of GOx were optimized yielding to a sigmoidal-shaped response with respect to the concentration in the $5-200 \mathrm{mg} \mathrm{dL}^{-1}$ range.
\end{abstract}

\section{Keywords}

Quantum dots; paper-based assay; glucose

\footnotetext{
To whom correspondence should be addressed (cdgarci@clemson.edu).
} 


\section{INTRODUCTION}

Luminescent quantum dots (QD) have been intensively used in recent years for the development of sensor and biosensors exploiting their fascinating optoelectronic properties [1-4]. Although most of these methods involve the use of QD as optical probes in the form of aqueous dispersions, less attention has been paid to their use in solid platforms, such as paper-based devices. In this regard, it is important to point out that paper is inexpensive, ubiquitous, robust, can be easily patterned [5,6], chemically modified, and have intrinsic wicking properties [7] rendering it advantageous for chemical and biological analysis. In addition, small volumes of reagents are necessary, resulting further reductions in cost. Therefore, paper-based analytical devices (including arrays [8]) have the potential to be widely adopted by the analytical community.

Many articles have reported the integration of nanomaterials in paper devices. However, the vast majority of these interesting developments have used gold [9] or silica [10] nanoparticles. Only a few reports have sought to integrate QD in paper devices. Among those, Petryayeva et al. reported a QD fluorescence resonance energy transfer (QD-FRET) assay on microfluidic paper devices based on the immobilization of the QD to thiol groups in the paper [11]. Noor et al. reported a quantitative DNA hybridization assay using spots of $\mathrm{CdS}_{\mathrm{X}} \mathrm{Se}_{1-\mathrm{X}} / \mathrm{ZnS}$ (core/shell) QD, also chemically immobilized on a paper substrate [12]. In this case, the immobilization of $\mathrm{CdS}_{\mathrm{x}} \mathrm{Se}_{1-\mathrm{x}} / \mathrm{ZnS} \mathrm{QD}$ was carried out by the modification of the paper substrates with imidazole ligands. Additional modifications were recently introduced by the same group [13]. Yuan et al. reported the use of polymer CdTe QDenzyme hybrid films incorporated on paper substrates to probe the presence of a corresponding substrate for the enzyme (tyrosinase or glucose oxidase) [14]. In this case, the quenching of photoluminescence was used as analytical signal for determine substrate concentration due to the conversion of substrates into products quenched the photoluminescence of QD. It is thus clear that these methods require not only the implementation of chemical modification protocols (for paper and/or QD), which may affect the activity of the enzyme and in consequence, impair the efficiency of the sensor $[15,16]$. Moreover, most of the sensing strategies involving QD require a bench-top detection system [17], therefore limiting the applicability with respect to the most traditional visual detection approach $[18,19]$.

To overcome these shortcomings this report describes a simple approach for the preparation of colloidal CdSe/ZnS QD and their use in an optical paper-based assay for glucose. Glucose was selected as a model system because it is important for several fields including biology [20,21], biochemistry [22], and food science [23].

\section{MATERIAL AND METHODS}

\section{Reagents and materials}

All chemical reagents used in the experiments were analytical grade and used as received. Cadmium oxide (CdO, $299.99 \%$ metal basis), trioctylphosphine oxide (TOPO, $99 \%$ ), trioctylphosphine (TOP, $90.0 \%$ ), selenium (Se powder, 100 mesh, $99.99 \%$ metals basis), diethylzinc solution $\left.\left(\mathrm{ZnEt}_{2}, 1 \mathrm{~mol} \cdot \mathrm{L}^{-1} \text { in hexane), bis(trimethylsilyl) sulfide ((TMS }\right)_{2} \mathrm{~S}\right)$, 
hexylphosphonic acid (HPA), methanol, and anhydrous chloroform were purchased from Sigma-Aldrich (St. Louis, MO, USA - http://www.sigmaaldrich.com/). These reagents were used to prepare CdSe/ZnS QD. a-D-Glucose and glucose oxidase (GOx, Type II, 17300 $\mathrm{U} \cdot \mathrm{g}^{-1}$, from Aspergillus niger) were also purchased from Sigma-Aldrich (St. Louis, MO, USA). Sodium phosphate dibasic anhydrous and hydrogen peroxide (30\% solution, certified) were acquired from Fischer Scientific (Pittsburgh, PA, USA - https:// www.fishersci.com/). All solutions were made in ultrapure water (18 M $\Omega . c m$, Barnstead Nanopure; Dubuque, IA, USA - http://www.thermoscientific.com/en/product/barnsteadnanopure.html). The paper substrate (Whatman grade 1 chromatography paper, Grade 1 CHR) was purchased from Whatman (Maidstone, Kent, UK - www.gelifesciences.com/ whatman). The plastic supports (acrylic sheets, $3 \mathrm{~mm}$ ) were fabricated with standard PMMA purchased from GravoTech, Inc. (Duluth, GA 30096 USA - http://www.gravograph.com/ english/engraving-products/). Analytical standard stock solutions of aD-glucose were prepared in buffer solution $\left(10 \mathrm{mmol} \cdot \mathrm{L}^{-1}, \mathrm{pH}=7\right)$. The stock solutions were stored under refrigeration conditions $\left(4{ }^{\circ} \mathrm{C}\right)$ and protected from the light. The stock solution of Se/TOP was prepared using $0.051 \mathrm{~g}$ of Se in $3 \mathrm{~mL}$ of TOP. Buffer solutions were prepared dissolving sodium phosphate dibasic anhydrous in ultrapure water and the $\mathrm{pH}$ was fixed using either sodium hydroxide or hydrochloric acid.

\section{Instrumentation}

Although many other methods can be selected to cut the circular spots for the assay (hole punch, scissors, etc), laser engraving was selected because it provides a simple way to produce the spots with reproducible dimensions and hydrophobic, regular edges that minimize gradients in the distribution of reagents (due to capillary action during the drying process). For the described experiments, a legend Mini24 $\mathrm{CO}_{2}$ Laser System (Epilog Laser Systems; Golden, CO, USA) was utilized in vector mode (100\% speed, $20 \%$ power, and $2300 \mathrm{~Hz}$ ) [24]. In order to minimize the possibility of ignition of the paper inside the engraver, the engraving head was constantly used to impinge a stream of $\mathrm{N}_{2}$ on the engraving spot. In order to avoid release of smoke (produced during the engraving process) into the working environment, the vent of the engraver was connected to an air filter (model AD350, BOFA; Staunton, IL) equipped with a HEPA/activated aluminum/potassium permanganate and an activated carbon panel. CorelDraw X6, by Corel Corp. (Ottawa, Canada), was used to design the geometry and cutting sequence of the paper substrates. A handheld UV lamp model UVLS-28 (Upland, CA 91786, USA) 115 V 60 Hz, 0.16 Amps with long $(365 \mathrm{~nm})$ and short $(254 \mathrm{~nm})$ wave assembly was used to activate and read the fluorescence from the QD. A standard Panasonic camera, DMC-TZ10 model was used to image the resulting substrates. Fluorescence was then analysed by measuring the color intensity of the spots by using Photoshop. To improve the selectivity of the measurement, the image was first decomposed in the RGB domains and then analysed using the average intensity in the red channel. A spectrophotometer Genesys 10-S Thermo (Electron Corporation; Madison, WI) and a Tecan Infinity M200 Quad monochrometer microplate (UV-Vis and fluorescence) spectrometer were used for the optical characterization of the synthesized QD. A JEOL 2010-F Field Emission Transmission Electron Microscope (TEM) was used to verify the shape and size of the QD. 


\section{Preparation of CdSe/ZnS QD}

The synthesis of the $\mathrm{CdSe} / \mathrm{ZnS}$ core/shell QD was performed using a modified version of the process reported by Peng et al [25]. Details regarding the synthesis are described in the Electronic Supporting Materials.

\section{Preparation of QD modified paper substrates and glucose detection}

Circular spots of paper of $0.4 \mathrm{~cm}$ diameter were cut in a $\mathrm{CO}_{2}$ laser engraver. A quantity of 9 $\mu \mathrm{L}$ (7.8 pmol) of a solution of QD in chloroform was dispensed on the center of the spot. After the solvent was evaporated, $3 \mu \mathrm{L}$ of a solution of phosphate buffer $(10 \mathrm{mM}, \mathrm{pH}=7)$ were added and the QD modified-paper substrates were activated under UV lamp (at excitation of $365 \mathrm{~nm}$ ) for $20 \mathrm{~min}$. No significant differences in fluorescence intensity were observed upon several washing steps (data not shown) suggesting that the QD are retained within the paper structure. For glucose detection, $20 \mathrm{mg} \cdot \mathrm{mL}^{-1}$ of GOx was added to QDmodified paper substrates and allowed to dry at room temperature for $5 \mathrm{~min}$. Then, $3 \mu \mathrm{L}$ of a solution of glucose were added and the reaction was performed for $20 \mathrm{~min}$, and the color developed read under a UV-vis lamp (365 nm) using a digital camera.

\section{Detection Scheme}

The mechanism used for the detection of glucose is based on the conversion by the enzyme (GOx) into D-glucono- $\delta$-lactone and $\mathrm{H}_{2} \mathrm{O}_{2}[26,27]$. The latter is then used to etch the surface of the QD and change their optical properties, resulting in a decrease in their fluorescence (schematic representation included as Electronic Supporting Materials). Although this mechanism has been reported for the analysis of multiple analytes it is important to note that the selectivity of the process can be limited by secondary processes affecting the surface of the QD [28].

\section{RESULTS AND DISCUSSION \\ Characterization of TOPO-CdSe/ZnS QD}

In order to obtain the optical properties of the synthesized QD, absorbance and fluorescence spectra were initially collected. Figure 1 shows representative results obtained with a suspension of the QD in chloroform.

As it can be observed, wide absorption band was obtained in the 300 to $600 \mathrm{~nm}$ range, with a well-defined emission peak at $612 \mathrm{~nm}$. These results were used to support the use of a standard hand-held UV lamp $(365 \mathrm{~nm})$ for the excitation and to select the color channel (red in the RGB scale) for the optical analysis of the results. Moreover, following a report from Yu et.al. [29], the diameter of purified CdSe/ZnS QD was calculated using Equation 1,

$$
D=\left(1.6122 \times 10^{-9}\right) \lambda^{4}-\left(2.6575 \times 10^{-6}\right) \lambda^{3}+\left(1.642 \times 10^{-3}\right) \lambda^{2}-(0.4277) \lambda+41.47 \quad \text { Equation }
$$

where $\mathrm{D}$ is the diameter of the nanocrystals $(\mathrm{nm})$ and $\lambda$ is the wavelength of maximum absorbance (corresponding to the first excitonic absorption peak of the crystal). In this case, an average diameter was calculated to be $3.46 \mathrm{~nm}$. This calculation was complemented by examining the produced QD using electron microscopy (representative results shown in 
Figure 2). As it can be observed, a homogeneous distribution of QD (size and shape) was obtained. In agreement with the theoretical calculation, the average size measured was 3.5 $\pm 0.5 \mathrm{~nm}(\mathrm{n}=25)$.

Based on a report by Adam et al. [30], the diameter of the QD was also used to calculate the concentration of QD by UV-Vis spectrophotometry using the Lambert-Beer relationship $(\varepsilon=$ $\left.5857 \mathrm{D}^{2.65}\right)$.

\section{Optimization of relevant variables}

The current literature suggests that a chemical modification of the paper substrate or a conjugation of QD is necessary to immobilize QD [14,12,11]. However, here we provide evidence that simpler and faster options for immobilization of QD to paper substrates are also possible. For this purpose the deposition of QD on the paper substrate and the optical response (fluorescence quenching) were investigated as a function of the (a) amount of QD deposited on the paper, (b) sample $\mathrm{pH}$ value, (c) photoactivation time, (d) reaction time, (e) enzyme loading, and (f) storage time. From these experiments (results provides as Electronic Supporting Materials) it was determined that (a) the minimum concentration necessary to cover the entire paper surface was $7.8 \mathrm{pmol}(9 \mu \mathrm{L})$ and that the best response was obtained when (b) a pH value of 7, (c) a photoactivation time of $20 \mathrm{~min}$, (d) a reaction time of $15 \mathrm{~min}$, and (e) $3 \mu \mathrm{L}$ of a solution containing $20 \mathrm{mg} \cdot \mathrm{mL}^{-1}$ of GOx were used [31]. It was also determined that under these conditions, the sensors showed only slight variations in the fluorescence intensity, accounting for an average difference of less than $1 \%$ during the first 7 days and only $7 \%$ during a 10-month period.

\section{Calibration plot for glucose}

In order to measure the influence of the concentration of glucose on the signal intensity of the QD-modified paper devices (prepared using the previously optimized conditions), calibration curves were developed using standards in the $0-200 \mathrm{mg} \cdot \mathrm{dL}^{-1}$ range. As it is depicted in Figure 3A, a progressive quenching of the initial fluorescence intensity was observed as the glucose concentration increased. The dynamic range obtained by using these results yielded a sigmoidal-shaped decay of the fluorescence with respect to the glucose concentration in the $5-200 \mathrm{mg} \cdot \mathrm{dL}^{-1}$ range. The change in the color intensity can be evidenced calculating the first derivative of the response, as shown in Figure 3B.

This fact demonstrates that the design of CdSe/ZnS QD modified paper spots can be a convenient As an example of the capabilities of the paper-based assay, the detection of glucose in a commercial dietary supplement (ReliOn, Pomegranate) was performed obtaining a $112 \%$ recovery with respect to the declared value.

It was also noted that as the intensity in the red channel (from the RGB image) decreased, an increase in the blue channel was also observed. Using this optical approach, the developed QD-modified paper-based assay may be used as a screening method for glucose in blood samples: a red color corresponds to normal values $\left(<100 \mathrm{mg} \cdot \mathrm{dL}^{-1}\right)$ whereas a blue color corresponds to abnormal values $\left(>150 \mathrm{mg} \cdot \mathrm{dL}^{-1}\right)$. The intermediate color gradient (mixture of red and blue color) corresponds to samples containing glucose concentrations in the 100$150 \mathrm{mg} \cdot \mathrm{dL}^{-1}$ range. Although complex samples containing abundant amount of proteins or 
dyes are expected to quench the fluorescence of QD, future modifications of the proposed screening method can be very useful as fast spot-test for clinical applications.

\section{Critical Assessment}

In order to summarize specific features of the described method, representative reports describing the analysis of glucose using QD are included in Table 1. Although other groups have reported LOD that are significantly lower than the one obtained with our QD-modified paper-based assay, the vast majority of them are based on traditional fluorometric detection. Compared to those reports, this method is simpler, requires minimal skills and instrumentation, and provides a dynamic range relevant to the clinical field. Furthermore, the platform herein described does not require chemical modification of the paper and/or the QD.

\section{CONCLUSIONS}

The presented results describe the design and fabrication of a QD-modified paper-based assay for glucose. The proposed assay is simple, inexpensive, does not involve cumbersome procedures for the immobilization of the enzyme to the surface of the QD, and requires minute sample volumes (only $3 \mu \mathrm{L}$ ). In addition to the low concentrations of QD (7.8 pmol) used, the biosensing potential of the strong and stable fluorescence emission of QD (under a standard handheld UV lamp) was demonstrated. Given these advantages, we believe this work may open new avenues to use CdSe/ZnS QD in the development of paper-based analytical devices and their applications in biomedical research, particularly as rapid screening methods.

\section{Supplementary Material}

Refer to Web version on PubMed Central for supplementary material.

\section{Acknowledgments}

This work was supported in part by he National Institute of Health through the National Institute of General Medical Sciences (2SC3GM081085), the Research Centers at Minority Institutions (G12MD007591), and the projects CTQ2013-48411-P (MINECO of Spain) and PEIC-2014-001-P (JCCM). Gema M. Durán thanks to MINECO of Spain for the predoctoral (BES-2011-045438) and stay (EEBB-I-14-08461) grants.

\section{References}

1. Duong HD, Rhee JI. Use of CdSe/ZnS core-shell quantum dots as energy transfer donors in sensing glucose. Talanta. 2007; 73(5):899-905. [PubMed: 19073118]

2. Durán GM, Contento AM, Ríos Á. Use of Cdse/ZnS quantum dots for sensitive detection and quantification of paraquat in water samples. Anal Chim Acta. 2013; 801(0):84-90. [PubMed: 24139578]

3. Durán GM, Plata MR, Zougagh M, Contento AM, Ríos Á. Microwave-assisted synthesis of water soluble thiol capped $\mathrm{CdSe} / \mathrm{ZnS}$ quantum dots and its interaction with sulfonylurea herbicides. J Colloid Interf Sci. 2014; 428(0):235-241.

4. Durán GM, Contento AM, Ríos Á. $\beta$-Cyclodextrin coated CdSe/ZnS quantum dots for vanillin sensoring in food samples. Talanta. 2015; 131(0):286-291. [PubMed: 25281104] 
5. Bhakta SA, Borba R, Taba M Jr, Garcia CD, Carrilho E. Determination of nitrite in saliva using microfluidic paper-based analytical devices. Anal Chim Acta. 2014; 809(0):117-122. [PubMed: 24418141]

6. de Tarso Garcia P, Garcia Cardoso TM, Garcia CD, Carrilho E, Tomazelli Coltro WK. A handheld stamping process to fabricate microfluidic paper-based analytical devices with chemically modified surface for clinical assays. RSC Advances. 2014; 4(71):37637-37644.

7. Evans E, Gabriel EFM, Coltro WKT, Garcia CD. Rational selection of substrates to improve color intensity and uniformity on microfluidic paper-based analytical devices. Analyst. 2014; 139(9): 2127-2132. [PubMed: 24618915]

8. Cheng C-M, Martinez AW, Gong J, Mace CR, Phillips ST, Carrilho E, Mirica KA, Whitesides GM. Paper-Based ELISA. Angew Chem Int Ed. 2010; 49(28):4771-4774.

9. Parolo C, Merkoci A. Paper-based nanobiosensors for diagnostics. Chem Soc Rev. 2013; 42(2):450457. [PubMed: 23032871]

10. Evans E, Moreira Gabriel EF, Benavidez TE, Tomazelli Coltro WK, Garcia CD. Modification of microfluidic paper-based devices with silica nanoparticles. Analyst. 2014; 139(21):5560-5567. [PubMed: 25204446]

11. Petryayeva E, Algar WR. Proteolytic Assays on Quantum-Dot-Modified Paper Substrates Using Simple Optical Readout Platforms. Anal Chem. 2013; 85(18):8817-8825. [PubMed: 23980758]

12. Noor MO, Shahmuradyan A, Krull UJ. Paper-Based Solid-Phase Nucleic Acid Hybridization Assay Using Immobilized Quantum Dots as Donors in Fluorescence Resonance Energy Transfer. Anal Chem. 2013; 85(3):1860-1867. [PubMed: 23272728]

13. Noor MO, Krull UJ. Camera-Based Ratiometric Fluorescence Transduction of Nucleic Acid Hybridization with Reagentless Signal Amplification on a Paper-Based Platform Using Immobilized Quantum Dots as Donors. Anal Chem. 2014; 86(20):10331-10339. [PubMed: 25225960]

14. Yuan J, Gaponik N, Eychmüller A. Application of Polymer Quantum Dot-Enzyme Hybrids in the Biosensor Development and Test Paper Fabrication. Anal Chem. 2012; 84(11):5047-5052. [PubMed: 22545809]

15. Wu M, Algar WR. Acceleration of Proteolytic Activity Associated with Selection of Thiol Ligand Coatings on Quantum Dots. Appl Mat Interfaces. 2015; 7(4):2535-2545.

16. Algar WR, Malonoski A, Deschamps JR, Blanco-Canosa JB, Susumu K, Stewart MH, Johnson BJ, Dawson PE, Medintz IL. Proteolytic Activity at Quantum Dot-Conjugates: Kinetic Analysis Reveals Enhanced Enzyme Activity and Localized Interfacial "Hopping". Nano Letters. 2012; 12(7):3793-3802. [PubMed: 22731798]

17. Santhiago M, Wydallis JB, Kubota LT, Henry CS. Construction and Electrochemical Characterization of Microelectrodes for Improved Sensitivity in Paper-Based Analytical Devices. Anal Chem. 2013; 85(10):5233-5239. [PubMed: 23581428]

18. Cate DM, Adkins JA, Mettakoonpitak J, Henry CS. Recent Developments in Paper-Based Microfluidic Devices. Anal Chem. 2015; 87(1):19-41. [PubMed: 25375292]

19. Song Y, Gyarmati P, Araújo AC, Lundeberg J, Brumer H, Ståhl PL. Visual Detection of DNA on Paper Chips. Anal Chem. 2014; 86(3):1575-1582. [PubMed: 24383957]

20. Rolland F, Baena-Gonzalez E, Sheen J. Sugar Sensing And Signaling In Plants: Conserved and Novel Mechanisms. Annu Rev Plant Biol. 2006; 57(1):675-709. [PubMed: 16669778]

21. Bhakta SA, Benavidez TE, Garcia CD. Immobilization of glucose oxidase to nanostructured films of polystyrene-block-poly(2-vinylpyridine). J Colloid Interface Sci. 2014; 430:351-356. [PubMed: 24980481]

22. Koschinsky T, Heinemann L. Sensors for glucose monitoring: technical and clinical aspects. Diabetes Metab Res Rev. 2001; 17(2):113-123. [PubMed: 11307176]

23. Terry LA, White SF, Tigwell LJ. The Application of Biosensors to Fresh Produce and the Wider Food Industry. J Agric Food Chem. 2005; 53(5):1309-1316. [PubMed: 15740000]

24. Gabriel EFM, Coltro WKT, Garcia CD. Fast and versatile fabrication of PMMA microchip electrophoretic devices by laser engraving. Electrophoresis. 2014; 35(16):2325-2332. [PubMed: 25113407] 
25. Peng ZA, Peng X. Formation of High-Quality CdTe, CdSe, and CdS Nanocrystals Using CdO as Precursor. J Am Chem Soc. 2001; 123(1):183-184. [PubMed: 11273619]

26. Chen C, Xie Q, Yang D, Xiao H, Fu Y, Tan Y, Yao S. Recent advances in electrochemical glucose biosensors: a review. RSC Advances. 2013; 3(14):4473-4491.

27. Oliver NS, Toumazou C, Cass AEG, Johnston DG. Glucose sensors: a review of current and emerging technology. Diabetic Med. 2009; 26(3):197-210. [PubMed: 19317813]

28. Xiangzhao A, Qiang M, Xingguang S. Nanosensor for dopamine and glutathione based on the quenching and recovery of the fluorescence of silica-coated quantum dots. Microchim Acta. 2013; 180(3-4):269-277.

29. Yu WW, Qu L, Guo W, Peng X. Experimental Determination of the Extinction Coefficient of CdTe, CdSe, and CdS Nanocrystals. Chem Mater. 2003; 15(14):2854-2860.

30. Adam S, Talapin DV, Borchert H, Lobo A, McGinley C, de Castro ARB, Haase M, Weller H, Möller T. The effect of nanocrystal surface structure on the luminescence properties: Photoemission study of HF-etched InP nanocrystals. J Chem Phys. 2005; 123(8):084706. [PubMed: 16164320]

31. Bhakta SA, Evans E, Benavidez TE, Garcia CD. Protein adsorption onto nanomaterials for the development of biosensors and analytical devices: A review. Anal Chim Acta. 2015; 872:7-25. [PubMed: 25892065]

32. Zhang X, Liu M, Liu H, Zhang S. Low-toxic Ag2S quantum dots for photoelectrochemical detection glucose and cancer cells. Biosens Bioelectron. 2014; 56:307-312. [PubMed: 24525014]

33. Zhang X, Xu F, Zhao B, Ji X, Yao Y, Wu D, Gao Z, Jiang K. Synthesis of CdS quantum dots decorated graphene nanosheets and non-enzymatic photoelectrochemical detection of glucose. Electrochim Acta. 2014; 133:615-622.

34. Hu B, Zhang L-P, Chen M-L, Chen M-L, Wang J-H. The inhibition of fluorescence resonance energy transfer between quantum dots for glucose assay. Biosens Bioelectron. 2012; 32(1):82-88. [PubMed: 22192453]

35. Wang G-L, Hu X-L, Wu X-M, Li Z-J. Quantum dots-based glucose sensing through fluorescence quenching by bienzyme-catalyzed chromogenic substrate oxidation. Sensors Actuat B-Chem. 2014; 205:61-66.

36. Lv X, Wang X, Huang D, Niu C, Zeng G, Niu Q. Quantum dots and p-phenylenediamine based method for the sensitive determination of glucose. Talanta. 2014; 129:20-25. [PubMed: 25127560]

37. Li Y, Ma Q, Liu Z, Wang X, Su X. A novel enzyme-mimic nanosensor based on quantum dot-Au nanoparticle@silica mesoporous microsphere for the detection of glucose. Anal Chim Acta. 2014; 840:68-74. [PubMed: 25086895]

38. Azizi SN, Chaichi MJ, Shakeri P, Bekhradnia A. Quantum dots and ionic liquid-sensitized effect as an efficient and green catalyst for the sensitive determination of glucose. Spectrochim Acta A Mol Biomol Spectrosc. 2015; 146:277-285. [PubMed: 25819316] 


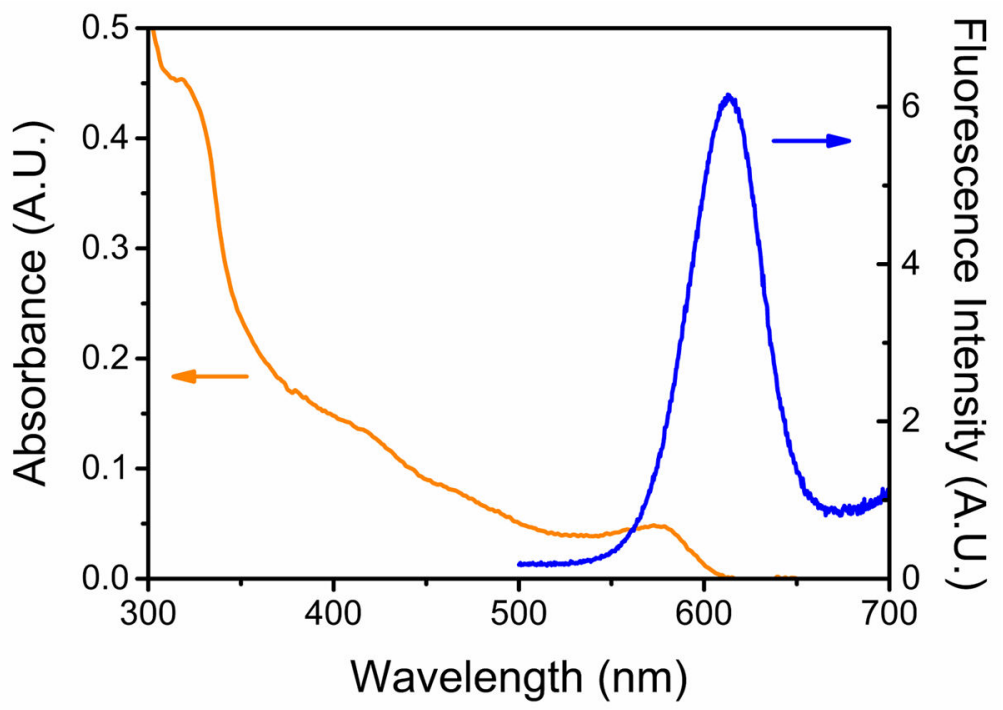

Figure 1.

(A) UV-visible absorption and fluorescence spectra of $0.3 \mu \mathrm{mol} \cdot \mathrm{dL}^{-1} \mathrm{CdSe} / \mathrm{ZnS}$ QD in chloroform 


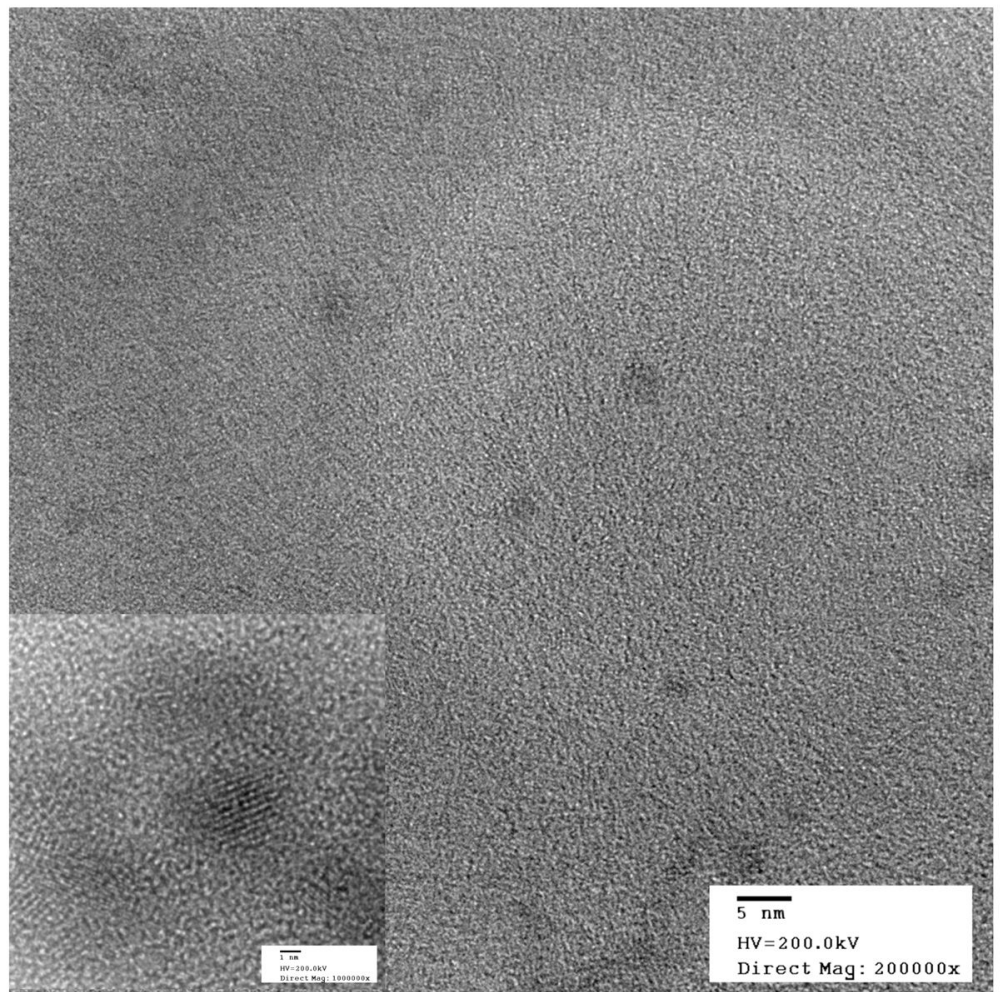

Figure 2.

Transmission electron microscopy images of CdSe/ZnS QD. 

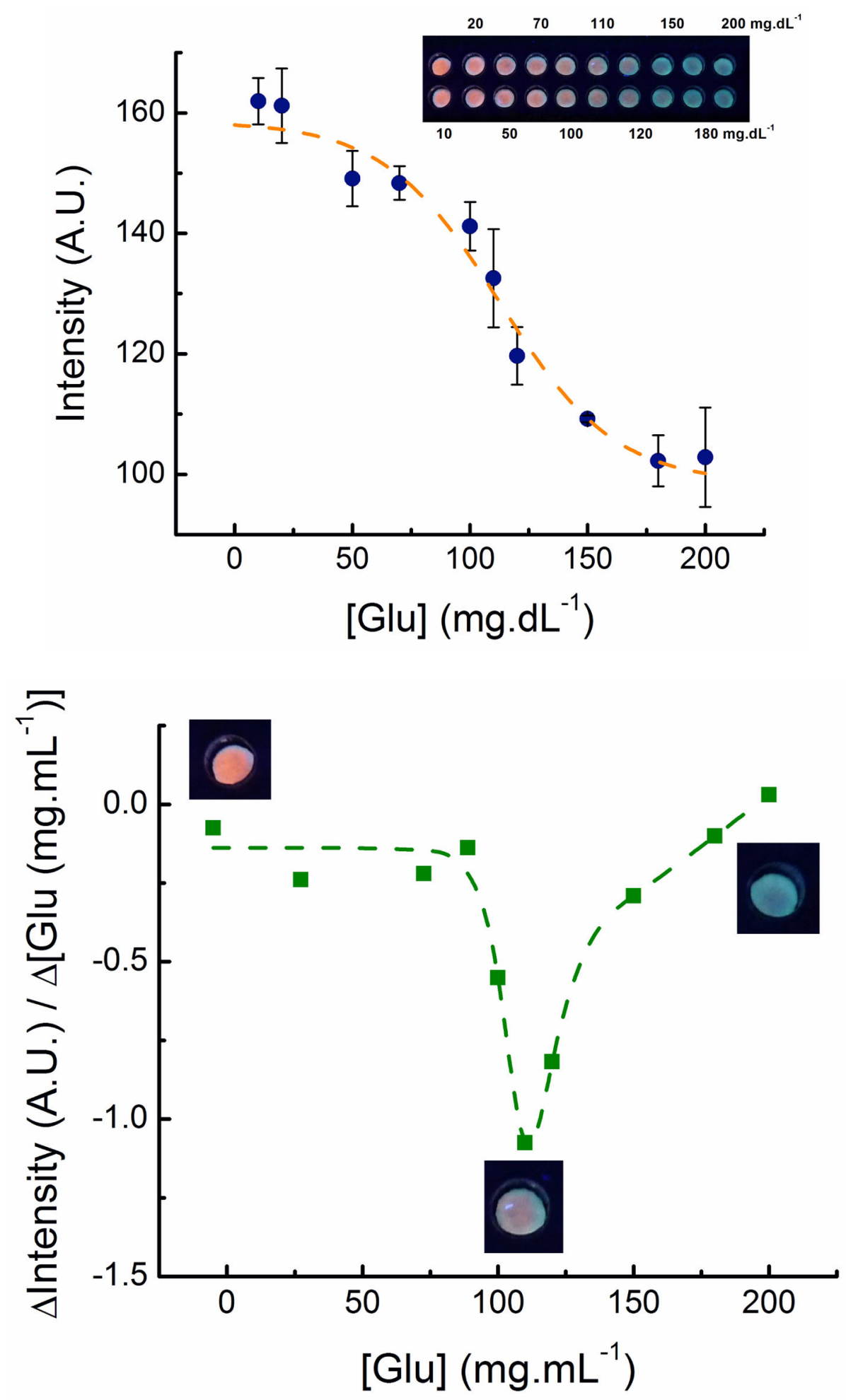

Figure 3. 
Quenching effects of QD towards different concentrations of glucose (A), and first derivative of the initial data showing the capability of the method to be used as a screening method for glucose (B). Lines included to guide the eye. 


\section{Table 1}

Analytical figures of merit of recent glucose sensors based on QD

\begin{tabular}{|c|c|c|c|c|}
\hline QD Material & Features & Analytical range $\left(\mathrm{mg} \cdot \mathrm{dL}^{-1}\right)$ & LOD $\left(\mu \mathrm{g} \cdot \mathbf{d} \mathrm{L}^{-1}\right)$ & Ref. \\
\hline $\mathrm{Ag}_{2} \mathrm{~S}$ & Photoelectrochemical & $2-220$ & 0.6 & {$[32]$} \\
\hline CdS-graphene & Non-enzymatic photoelectrochemical & $2-72$ & 0.1 & {$[33]$} \\
\hline $\mathrm{CdTe} / \mathrm{TGA}$ & FRET competitive assay & $2-36$ & 0.5 & {$[34]$} \\
\hline $\mathrm{CdS}$ & $\begin{array}{l}\text { Bienzymatic substrate oxidation of two chromogenic } \\
\text { agents }\end{array}$ & $\begin{array}{l}0.009-180(\mathrm{OPD}) \\
0.002-18(\mathrm{DAB})\end{array}$ & $\begin{array}{l}0.002(\mathrm{OPD}) \\
0.0004(\mathrm{DAB})\end{array}$ & {$[35]$} \\
\hline $\mathrm{Mn}: \mathrm{CdS} / \mathrm{ZnS}$ & $\begin{array}{l}\text { Hybrid system-based reaction of p-phenylenediamine with } \\
\mathrm{H}_{2} \mathrm{O}_{2}\end{array}$ & $0.09-180$ & 0.06 & [36] \\
\hline $\mathrm{CdTe} @ \mathrm{SiO}_{2}-\mathrm{Au}$ & Enzyme-mimic nanosensor & $0.09-3.6$ & 0.02 & [37] \\
\hline CdTe@PDDA & Hybrid system-based on quenching & $0.2-9$ & 0.09 & [14] \\
\hline CdSe@IL/copper & Fluorometric method with IL/copper as catalyst & $0.009-1.8$ & 0.002 & {$[38]$} \\
\hline $\mathrm{CdSe} / \mathrm{ZnS}$ & Paper-based optical & $5-200$ & 5 & this work \\
\hline
\end{tabular}

